\title{
Regulatory role of defensins in inflammatory bowel disease
}

\author{
Chi Chen", Praveen Kumar Yadav, Xingpeng Wang, Zhanju Liü
}

Department of Gastroenterology, The Shanghai Tenth People's Hospital, Tongji University School of Medicine, Shanghai, China;

${ }^{\#}$ Corresponding Author: zhanjuliu@yahoo.com

Received 7 January 2012; revised 13 February 2012; accepted 23 February 2012

\begin{abstract}
Defensins are endogenous antimicrobial peptides (AMPs) produced by professional phagocytes, Paneth cells, and epithelial cells at mucosal surfaces, which mediate innate immunity through their potent antimicrobial activity in the intestinal tract. In addition, defensins also regulate the function of diverse host immune cells, thereby play an important role in both innate and adaptive immune responses against pathogenic microbes. Abundant evidences have proved that attenuated changes in defensins expression are observed in inflammatory bowel disease (IBD). Further studies have discovered the concentration of different defensins subgroups has the relationship with various clinical characteristics of IBD and that mucosal surface destruction causes defensins deficiency as a result of inflammatory damage. This article is to review new current approaches on defensins expression in the intestinal mucosa, particularly in IBD and their potential roles in immune responses in the gut mucosa.
\end{abstract}

Keywords: Defensins; Inflammatory Bowel Disease

\section{INTRODUCTION}

Inflammatory bowel disease (IBD) is chronic, relapsing disease of the gastrointestinal tract. IBD includes two conditions, ulcerative colitis (UC) and Crohn's disease (CD) which shares a number of common characteristics. However, notable differences are also observed in these disorders. UC shows the pathological features of a significant number of leukocyte infiltrations within the lamina propria and the crypts, where they form microabscesses, as well as depletion of mucin by goblet cells. CD may be patchy, segmental and typically transmural

*Department of Gastroenterology, Shanghai East Hospital, Tongji University School of Medicine, China. inflammation in the gut [1], which is characterized by aggregation of macrophages that frequently form noncaseating granulomas.

The precise pathogenesis of IBD remains elusive, environmental factors such as microorganisms, genetic factors and immune disorders may contribute to the occurrence of IBD [2-4]. Intestinal mucosal surfaces are colonized by a diverse and dynamic microbiota. Experimental studies have provided evidences that these colonizing microbes are essential to host development and homeostasis. Many studies have implied that they are essential to the pathological inflammation and may mediate both innate and adaptive responses underlying the chronic inflammation [5]. The most commonly accepted etiology of IBD is loss of tolerance to commensal bacteria and important pathogenic mechanisms of the innate immune system response.

Thus, the interest in the innate immune function in IBD pathogenesis has led to the research of host immune defense response. Defensins are member of the antimicrobial peptides (AMPs) family. They are endogenous antibiotics with microbicidal activity against a wide variety of bacteria and protect the host from the gastrointestinal tract pathogens. Recent evidence suggests that they can act with host immune cells, thereby playing important roles in both the innate and adaptive immune responses [6-8]. The expression and regulation of defensins produced in the intestinal mucosa have been proved to be altered in IBD. But it is not clear whether the abnormal defensins production is a pathogenic factor in IBD or the consequence of epithelial damage. Many researches argued that decreased expression of defensins is not a primary defect causing the disease but a consequence of Paneth cells resulting in an increased production of defensins in the colon [9]. Thus, the bacterial invasion of the mucosa could not be controlled and the inflammation got into a perpetuation.

\section{THE SUBTYPES AND EXPRESSION OF DEFENSINS}

Defensins are the most-studied family of gene-en- 
coded antimicrobial peptides which is an important component of the innate immune systems $[10,11]$. The defensins molecules contain fewer than 100 amino acids and molecular weight ranging from 3000 to 4500 [12]. Defensins possess a characteristic single chain structure containing 6 cysteine residues with 3 intramolecular disulfide bonds [13]. They can be divided into three subgroups ( $\alpha$-, $\beta$ - and $\theta$-defensins) according to the different pattern of three cysteine linkages [14]. $\alpha$-defensins and $\beta$ defensins exit in the species of primates, rodents, ruminants, birds, crustaceans and rabbits, whereas $\theta$-defensins can only be found in non-human primates. Therefore, this review will focus on the role of $\alpha$ - and $\beta$-defensins.

Defensins are abundant in cells and tissue. Human $\alpha$ defensins have been identified as six members, human neutrophil peptide defensins 1-4 (HNP-1, HNP-2, HNP-3 and HNP-4) which are localized in azurophilic granules of circulating neutrophils. In gastrointestinal tract, $\alpha$-defensins are highly expressed and largely confined to the small intestine, in accordance with the presence of lamina propria neutrophils [15]. In contrast, the other two human defensin-5 (HD-5) and defensin-6 (HD-6) (also known as DEFA5 and DEFA6) are expressed at the base of crypts in small intestine [16]. Paneth cells are the major source of these two enteric defensins in the small bowel [17].

On the other hand, the human $\beta$-defensins (HBD) include 4 subgroups which are expressed at multiple sites, HBD-1, HBD-2, HBD-3 and HBD-4 [18]. In contrast, $\beta$ defensins are absent from human neutrophils or Paneth cells. In the colon, epithelial cells and plasma cells in the lamina propria are the major cells produce HBD. Epithelial cells constitutively express HBD-1 at mucosa sites. HBD-2, 3 and 4 is induced at sites of infection or inflammation by various bacterial stimuli. Colonic plasma cells also express HBD-2, 3 and 4 however it still remains unclear whether this expression is constitutive or inducible [19].

\section{BIOLOGICAL ACTIVITIES OF DEFENSINS}

Defensins are produced by professional phagocytes, Paneth cells, and epithelial cells, etc. Their wide spread expression suggests that defensins play an important role in the maintenance of a stable microbial population. Defensins have microbicidal activities against Gram-positive and Gram-negative bacteria, fungi and certain enveloped viruses [20,21]. Like other cationic antimicrobial peptides, the bactericidal mechanism of defensins is thought to disrupt membrane integrity of the target cell, so-called "Shai-Matsuzaki-Huang model" [22-24]. Defensins interact with the phospholipid groups on the target cell outer membrane, replace for those lipids, and weaken the membrane. As a result, the process will cause the disintegration of the membrane into vesicles.

Intestinal $\alpha$-defensins, especially human $\alpha$-defensin HD5 , are active against many bacterial species such as Grampositive bacteria (e.g. Listeria monocytogenes and $S$. aureus), Gram-negative bacteria (e.g. E. coli and S. typhimurium), and the fungus $C$. albicans [25,26]. Surprisingly, human $\alpha$-defensin HD- 6 has very poor antibacterial activity in vitro, despite similar ionic charge properties to HD-5 [27]. Human $\beta$-defensins HBD-1, like HD-6, has less antibacterial activity. Other human $\beta$ defensins expressed mostly in the stomach and colon, have bactericidal activity but are not broad-spectrum antimicrobial peptides. HBD-2 develops specificity against Gram-negative bacteria such as $P$. aeruginosa and E. coli, but shows lesser activities against Gram-positive bacteria. In contrast, HBD-3 has more potent activity against Gram-positive bacteria (e.g. S. aureus) [28]. Defensins also have effects on the colonizing intestinal microbiota because some microbes may be more sensitive than others. Thus, the composition of the microbial population keeps being shaped by these peptides.

\section{IMMUNE REGULATORY ROLES OF DEFENSINS}

Large amounts of evidences have suggested that defensins can interact with host immune cells, provide a link between innate immune responses and adaptive immunity [29]. The interest in the innate and adaptive immune response in IBD pathogenesis has led to more and more research for evaluating the altered expression of defensins and revealing their potential immune regulatory roles [30].

\subsection{Defensins in Innate Immunity}

The innate immunity is the most primitive defense system against pathogens. As an important component of the innate host defense, defensins protect the epithelium and stem cells by deactivating various microbial pathogens and specific bacterial exotoxins in the gastrointestinal tract [31]. Human $\alpha$-defensins, especially HNPs and HD5, are well documented to have antimicrobial and immune activity against enteric pathogens [32,33]. This antimicrobial function of defensins allows gastrointestinal mucosa to maintain the balance between protection from pathogens and tolerance to normal flora [34]. Decreased expression or attenuated function of defensins results in an increase in frequency and severity of intestinal infections [35]. Many studies have manifested that defensins deficiency is a primary event in IBD pathogenesis, which leads to bacterial invasion and inflammation. 


\subsection{Defensins in Adaptive Immunity}

Furthermore, defensins could serve as a bridge between the innate immunity and subsequent adaptive immune responses. Intestinal defensins act as chemotactic factors for $\mathrm{T}$ cells, monocytes and immature dendritic cells, benefit for the start of acquired immune response and help immune cell recruitment. HNP 1-3 can selectively chemo-attract monocytes, naive $\mathrm{T}$ and immature dendritic cells via a G-protein-coupled receptor [36]. HNP-1 and HNP-2 could promote severe combined immune deficiency (SCID) mice T cell recycling. Human $\beta$-defensins induce the migration of both human resting memory $\mathrm{T}$ cells and immature dendritic cells by interacting with the chemokine receptor (CCR) 6, promote adaptive immune responses consequently [37]. Some work has also shown that HBD2 has the similar structure with the natural CC chemokine ligand (CCL) 20 and could be an effective competitor [38]. As Toll-like receptor-4 (TLR4) endogenous ligand, HBD2 could combine with TLR-4, leading to nuclear factor- $\kappa \mathrm{B}$ (NF- $\kappa \mathrm{B})$ activation and migration to the nucleus to activate cytokine gene transcription, thereby activate $\mathrm{T}$ cells, and trigger a strong acquired immune response [39]. Many experiments found defensins administration in the animal immunized with tumor antigen could significantly enhanced the protective response to a syngeneic tumor antigen and also augmented resistance to tumor challenge by $\mathrm{T}$ cell-dependent cellular immunity and antigen-specific Ig production [40]. Changes in defensins expression may affect directly or indirectly the host innate and adaptive responses.

\section{DEFENSINS IN IBD}

Many studies have demonstrated the role of compromised defensins expression in human enteric diseases. Through the researches of $\alpha$-defensins (HD-5 and HD-6), the relationship betweeen defensins and Paneth cell have been revealed and $\alpha$-defensins are so-called Paneth cell defensins. More and more investigators have put the focus on the function of Paneth cell and its crucial position in the etiology of IBD has been established then. Unlike $\alpha$-defensins, $\beta$-defensins were produced by epithelial and plasma cells in the colon, but it is unclear whether this expression is constitutive or inducible. A defection of defensins at the epithelium could render the mucosa less efficient in killing bacteria and allow them to penetrate the epithelial barrier. Therefore, the role of defensins in the pathogenesis of IBD should be evaluated thoroughly.

\section{1. $\alpha$-Defensins in IBD}

Paneth cells are the major source of $\alpha$-defensins in the small intestine and located at the base of the crypts, thus indicating an essential role of protecting the epithelial stem cells. Paneth cells secrete varieties of antimicrobial proteins and peptide. Among which the two $\alpha$-defensins (HD-5 and HD-6) are the most abundant and expressed prenatally [41]. Recent studies provide evidence that reduced Paneth cell defensin expression may be a key pathogenic factor in ileal Crohn's disease. The hypothesis that reduced expression of $\alpha$-defensins could compromise mucosal host defenses and predisposes to the intestinal mucosal inflammation in the ileum has evolved recent years [42].

Some independent studies of IBD patients have showed decreased expression of $\alpha$-defensins (mRNA and protein) [43], whereas other have showed Paneth cell products remained unchanged or increased. This deficit was not observed in either $\mathrm{CD}$ of colon or UC, but only in the ileum of CD patients [44]. The specific decrease of $\alpha$ defensins was independent of the degree of inflammation in the specimens. The human and rodent studies further substantiate a link between nucleotide oligomerization domain 2 (NOD2, a critical intracellular recognition receptor for muramyl dipeptide) frame shift mutation and Paneth cell $\alpha$-defensins [45]. It is reported a decrease of Paneth cell $\alpha$-defensin mRNA expression in mice lacking the NOD2 gene. The NOD2 knockout mice were unable to detect muramyl dipeptide, the ligand for NOD2 [46]. The specific decrease in $\alpha$-defensins was more pronounced in the minority of patients that harbor a mutation in NOD2 [47]. This theory provides a novel mechanism for pathogenesis in patients with ileac CD. However, the underlying mechanism remains unclear.

Recent studies investigated the possible role of the Wnt signaling pathway and relationship with defensins expression in IBD. It was found that Wnt signaling pathway mediate the defensin deficit in the majority of patients who do not have mutations in NOD2. Wnt signaling, which is transduced through $\beta$-catenin/Tcf-4, has been shown to be a key regulatory circuit for Paneth cell differentiation and induce maturation of Paneth cells in intestinal crypts [48]. In rodent studies, Paneth cell gene program had been demonstrated critically dependent on Tcf-4 embryonic intestine [49]. This pathway is disturbed in ileal CD patients. Data indicated the presence of reduced expression of Wnt signaling transcription factor Tcf-4 in ileal CD, regardless of the degree of inflammation [50]. The levels of Tcf-4 mRNA in ileal IBD patients are decreased and showed a correlation with both HD-5 and HD-6 mRNA [51]. Moreover, the association between Paneth cell $\alpha$-defensins and Tcf- 4 was found to be independent of NOD2 genotype.

Other $\alpha$-defensins were also expressed in the intestinal epithelial cells but not in Paneth cells. Immunohistochemical analysis revealed that surface enterocytes strongly positive for HNP 1-3 seen in inflamed colonic mucosa [52]. These defensins mRNA increased in cases of active $\mathrm{CD}$ and $\mathrm{UC}$ and associated with the degree of inflamma- 
tion [53]. Whereas, the circulating HNP 1-3 levels are consistent with peripheral white blood cells and neutrophil counts in CD but not UC patients. The plasma concentrations of HNP 1-3 reflect the degree of inflammatory responses, and function as biomarkers for the disease activity of CD [54]. It is not clear whether intestinal inflammation results in epithelial expression of these defensins or simply they are taken up by enterocytes from adjacent neutrophils.

\section{2. $\beta$-Defensins in IBD}

Since colon is a complex ecosystem, to keep balance, epithelial cells provided a strong chemomechanical barrier, including the HBD-1 [55]. HBD-1 is constitutively expressed by normal colon epithelial cells. Evidences have revealed the variants in HBD-1 gene and colonic mucosa HBD-1 expression reduced in $\mathrm{CD}$ and $\mathrm{UC}$ patients at mRNA level [56]. Different single-nucleotide polymorphisms of HBD-1 have been showed to be associated with colonic CD [57]. Furthermore, HBD-1 is inversely associated with serological markers in CD patients, supporting its foundational defense functions in the mucosal immune [58]. The impaired induction of HBD-1, antimicrobial antiproteases elafin and the cathelicidin LL-37 became the characters of CD in the colon [59].

In contrast to HBD-1, the other HBDs were absent from the healthy colon. However, HBD-2, HBD-3 and HBD-4 expressions are induced by inflammation and bacterial stimuli in $\mathrm{CD}$ and $\mathrm{UC}$ patients [60]. Colonic synthesis of HBD 2-4 depends on NF- $\kappa$ B activation stimulated by inflammatory cytokines including tumor necrosis factor- $\alpha$ (TNF- $\alpha$ ) [61], indicating a defense response of HBD 2-4 in extended inflammation.

Recently, a lot of studies have shown that HBD-2 have a key role in leading to increased barrier function in the gut. In normal colon, low level of HBD-2 expression is present in the epithelium, but marked increase in flamed colon. HBD-2 mRNA expression is found to be higher in $\mathrm{UC}$ and $\mathrm{CD}$ patients compared to healthy controls. When comparing colonic HBD-2 expression among patients with $\mathrm{CD}$ and $\mathrm{UC}$, there is a striking difference: a strong HBD-2 induction seems to be attenuated in the inflamed tissue of $\mathrm{CD}$ patients [62]. In the meantime, HBD-2 has an obviously greater up-regulation in UC compared to colonic CD. In addition, there is significantly increased HBD-2 expression in the areas of active inflammation compared to non-inflamed areas [63]. Evidence suggests that NOD2 mediates the induction of HBD-2 in colonic $\mathrm{CD}$ and UC. Genetic studies have found that a lower HBD2 gene copy number in the $\beta$-defensin locus predisposes to the development of colonic CD [64].

Two $\beta$-defensins with a different antimicrobial spectrum, HBD-3 and HBD-4, seem to follow this distribution pattern, although their mRNA expression levels are lower
[65]. The colonic expression of HBD-3 and HBD-4 are also greater in UC than in control which has been confirmed by reverse-transcriptase polymerase chain reaction and by immunohistochemical staining of colonic epithelial cells. But there is no difference in expression between controls and patients with colonic CD [66]. It appears that HBD 3-4 could be up-regulated conesquently to the inflammatory events, and not likely have a role in the pathogenesis of the disease. However, further evidence of their role in the pathogenesis of IBD is required.

\section{CONCLUSION}

Defensins are multifunctional antibacterial peptides produced by professional phagocytes, Paneth cells, and intestinal epithelial cells. Defensins are not only antibiotic peptide with broad-spectrum activity against commensal microbiota, but also immune regulators that can modulate the function and movement of various cells, including neutrophils, monocytes, T-lymphocytes, dendritic cells, and epithelial cells. As an essential member of innate and adaptive immune responses which are directed against luminal bacteria in the gut, the deficiency in the expression and/or function of defensins could result in an increasing risk of intestinal infections. Increasing data have confirmed that such a deficiency could lead to a loss of tolerance to gut bacteria, gradual bacterial invasion and inflammation eventually. Several lines of evidences have substantiated the hypothesis that mucosal defensins play a pivotal role in the pathogenesis of IBD. The decreased level of $\alpha$-defensins constitutively produced by Paneth cells indicates its role in the maintenance of intestinal immune homeostasis. Moreover, the significantly increased expression of other inducible defensins suggests their potent effect on the condition of active inflammation. Thus, the impaired innate immunity due to defensins-deficiency may lead to altered adaptive immune responses. Although altered defensins expression in IBD is doubtless, it is less clear whether the deficiency is involved in the pathogenesis of IBD or is a consequence of the disease process. The accumulating research results about defensins will have a deep influence on future therapeutic strategies aimed at restoring the host homeostasis.

\section{ACKNOWLEDGEMENTS}

This work was supported by the Grants from the National Natural Science Foundation of China (Nos. 30971358 and 81061120521).

\section{REFERENCES}

[1] Xavier, R.J. and Podolsky, D.K. (2007) Unravelling the pathogenesis of inflammatory bowel disease. Nature, $\mathbf{4 4 8}$, 


\section{7-434. doi:10.1038/nature06005}

[2] Brown, S.J. and Mayer, L. (2007) The immune response in inflammatory bowel disease. The American Journal of Gastroenterology, 102, 2058-2069. doi:10.1111/j.1572-0241.2007.01343.x

[3] Mudter, J. (2011) What's new about inflammatory bowel diseases in 2011. World Journal of Gastroenterology, 17, 3177.

[4] Liu, Z., Yadav, P.K., Su, J.L., et al. (2009) Potential role of Th17 cells in the pathogenesis of inflammatory bowel disease. World Journal of Gastroenterology, 15, 57845788. doi:10.3748/wig. 15.5784

[5] Peyrin-Biroulet, L., Vignal, C., Dessein, R., et al. (2009) NODs in defence: From vulnerable antimicrobial peptides to chronic inflammation. Trends in Microbiology, 14, 432-438. doi:10.1016/j.tim.2006.08.008

[6] Peters, B.M., Shirtliff, M.E. and Jabra-Rizk, M.A. (2010) Antimicrobial peptides: Primeval molecules or future drugs? Public Library of Science Pathogens, 6, 1001067. doi:10.1371/journal.ppat.1001067

[7] Steinstraesser, L., Kraneburg, U., Jacobsen, F. and AlBenna, S. (2011) Host defense peptides and their antimicrobial-immunomodulatory duality. Immunobiology, 216, 322-333. doi:10.1016/j.imbio.2010.07.003

[8] Hazlett, L. and Wu, M. (2011) Defensins in innate immunity. Cell and Tissue Research, 343, 175-188. doi:10.1007/s00441-010-1022-4

[9] Arijs, I., De, Hertogh, G., Lemaire, K., et al. (2009) Mucosal gene expression of antimicrobial peptides in inflammatory bowel disease before and after first infliximab treatment. Public Library of Science Pathogens One, 4, 79-84. doi:10.1371/journal.pone.0007984

[10] Zasloff, M. (2002) Antimicrobial peptides of multicellular organisms. Nature, 415, 389-395. doi:10.1038/415389a

[11] Szyk, A., Wu, Z., Tucker, K., et al. (2006) Crystal structures of human alpha-defensins HNP4, HD5, and HD6. Protein Science, 15, 2749-2760. doi:10.1110/ps.062336606

[12] Duclohier, H. (2010) Antimicrobial peptides and peptaibols, substitutes for conventional antibiotics. Current Pharmaceutical, 16, 3212-3223. doi: $10.2174 / 138161210793292500$

[13] Tecle, T., Tripathi, S. and Hartshorn, K.L. (2010) Review: Defensins and cathelicidins in lung immunity. Innate Immunity, 16, 151-159. doi:10.1177/1753425910365734

[14] Underwood, M.A. and Bevins, C.L. (2010) Defensin-barbed innate immunity: Clinical associations in the pediatric population. Pediatrics, 125, 1237-1247. doi:10.1542/peds.2009-3289

[15] Zilbauer, M., Jenke, A., Wenzel, G., et al. (2011) Intestinal alpha-defensin expression in pediatric inflammatory bowel disease. Inflammatory Bowel Disease, 17, 2076-2086. doi:10.1002/ibd.21577

[16] Ferguson, L.R., Browning, B.L., Huebner, C., et al. (2008) Single nucleotide polymorphisms in human Paneth cell defensin A5 may confer susceptibility to inflammatory bowel disease in a New Zealand Caucasian population. Digestive and Liver Disease, 40, 723-730. doi:10.1016/j.dld.2008.02.011

[17] Shi, J. (2007) Defensins and Paneth cells in inflammatory bowel disease. Inflammatory Bowel Diseases, 13, 1284-1292. doi:10.1002/ibd.20197

[18] Ramasundara, M., Leach, S.T. and Lemberg, D.A. (2009) Defensins and inflammation: The role of defensins in inflammatory bowel disease. Journal of Gastroenterology and Hepatology, 24, 202-208. doi:10.2217/fmb.09.104

[19] Zilbauer, M., Jenke, A. and Wenzel, G.. (2010) Expression of human beta-defensins in children with chronic inflamematory bowel disease. Public Library of Science Pathogens, 5, e15389. doi:10.1371/journal.pone.0015389

[20] Kohlgraf, K.G., Pingel, L.C., Dietrich, D.E., et al. (2010) Defensins as anti-inflammatory compounds and mucosal adjuvants. Future Microbiology, 5, 99-113. doi: $10.2217 / \mathrm{fmb} .09 .104$

[21] Doss, M., White, M.R., Tecle, T., et al. (2010) Human defensins and LL-37 in mucosal immunity. Journal of Leukocyte Biology, 87, 79-92. doi:10.1189/jlb.0609382

[22] Bocchinfuso, G., Palleschi, A., Orioni, B., et al. (2009) Different mechanisms of action of antimicrobial peptides: Insights from fluorescence spectroscopy experiments and molecular dynamics simulations. Journal of Peptide Science, 15, 550-558. doi:10.1002/psc. 1144

[23] Cunliffe, R.N. (2003) Alpha-defensins in the gastrointestinal tract. Molecular Immunology, 40, 463-467. doi:10.1016/S0161-5890(03)00157-3

[24] Wehkamp, J., Schmid, M. and Stange, E.F. (2007) Defensins and other antimicrobial peptides in inflammatory bowel disease. Current Opinion in Gastroenterology, 23, 370-378. doi:10.1097/MOG.0b013e328136c580

[25] Cunliffe, R.N., Rose, F.R., Keyte, J., et al. (2001) Human defensin-5 (HD-5) is processed upon Paneth cell granule secretion, and its expression is induced inflammatory bowel disease (IBD). Gut, 48, 176-185. doi:10.1136/gut.48.2.176

[26] Ding, J., Chou, Y.Y. and Chang, T.L. (2009) Defensins in viral infections. Journal of Innate Immunity, 1, 413-420. doi:10.1159/000226256

[27] Simms, L.A., Doecke, J.D., Walsh, M.D., et al. (2008) Reduced alpha-defensin expression is associated with inflammation and not NOD2 mutation status in ileal Crohn's disease. Gut, 57, 903-910. doi:10.1136/gut.2007.142588

[28] Fu, L.B., Yu, J.L. and Liu, W.H. (2011) Biological characteristics of defensin and its disease-resistance genetic engineering. Hereditas, 33, 512-519. doi:10.3724/SP.J.1005.2011.00512

[29] Wehkamp, J., Koslowski, M., Wang, G., et al. (2008) Barrier dysfunction due to distinct defensin deficiencies in small intestinal and colonic Crohn's disease. Mucosal Immunology, 1, 67-74. doi:10.1038/mi.2008.48

[30] Rehaume, L.M. and Hancock, R.E. (2008) Neutrophilderived defensins as modulators of innate immune function. Critical Reviews in Immunology, 28, 185-200.

[31] Pazgier, M., Hoover, D.M., Yang, D., et al. (2006) Human beta-defensins. Cellular and Molecular Life Sciences, 63, 1294-1313. doi:10.1007/s00018-005-5540-2 
[32] Escribese, M.M., Rodriguez-Garcia, M., Sperling, R., et al. (2011) Alpha-defensins 1-3 release by dendritic cells is reduced by estrogen. Reproductive Biology and Endocrinology, 9, 118. doi:10.1186/1477-7827-9-118

[33] Milewski, L., Dziunycz, P., Barcz, E., et al. (2011) Increased levels of human neutrophil peptides 1, 2, and 3 in peritoneal fluid of patients with endometriosis: Association with neutrophils, T cells and IL-8. Journal of Reproductive Immunology, 91, 64-70. doi:10.1016/j.jri.2011.05.008

[34] Ouellette, A.J. (2011) Paneth cell $\alpha$-defensins in enteric innate immunity. Cellular and Molecular Life Sciences, 68, 2215-2229. doi:10.1007/s00018-011-0714-6

[35] Chamaillard, M. and Dessein, R. (2011) Defensins couple dysbiosis to primary immunodeficiency in Crohn's disease. World Journal of Gastroenterology, 17, 567-571. doi:10.3748/wjg.v17.i5.567

[36] Wu, Z., Ericksen, B., Tucker, K., et al. (2004) Synthesis and characterization of human alpha-defensins 4-6. The Journal of Peptide Research, 64, 118-125. doi:10.1111/j.1399-3011.2004.00179.x

[37] Nagaoka, I., Niyonsaba, F., Tsutsumi-Ishii, Y., et al. (2008) Evaluation of the effect of human beta-defensins on neutrophil apoptosis. International Immunology, 20, 543-553. doi:10.1093/intimm/dxn012

[38] Ghannam, S., Dejou, C., Pedretti, N., et al. (2010) CCL20 and $\beta$-defensin-2 induce arrest of human Th17 cells on inflamed endothelium in vitro under flow conditions. Journal Immunology, 186, 1411-1420. doi:10.4049/jimmunol.1000597

[39] Biragyn, A., Coscia, M., Nagashima, K., et al. (2008) Murine beta-defensin 2 promotes TLR-4/My D88-mediated and NF-kappaB-dependent atypical death of APCs via activation of TNFR2. Journal of Leukocyte Biology, 83, 998-1008. doi:10.1189/jlb.1007700

[40] Droin, N., Hendra, J.B., Ducoroy, P., et al. (2009) Human defensins as cancer biomarkers and antitumour molecules. Journal of Proteomics, 72, 918-927. doi:10.1016/j.jprot.2009.01.002

[41] Yadav, P.K., Chen, C. and Liu, Z. (2011) Potential role of NK cells in the pathogenesis of inflammatory bowel disease. Journal of Biomedicine Biotechnology, 2011, Article ID: 348530 .

[42] Wehkamp, J. and Stange, E.F. (2008) Is there a role for defensins in IBD? Inflammatory Bowel Diseases, 14, 85-87. doi:10.1002/ibd.20698

[43] Wehkamp, J., Salzman, N.H., Porter, E., et al. (2005) Reduced Paneth cell $\alpha$-defensins in ileal Crohn's disease. Proceeding of the National Academy of Sciences of the USA, 102, 18129-18134. doi:10.1073/pnas.0505256102

[44] Balducci, E., Bonucci, A., Picchianti, M., et al. (2011) Structural and functional consequences induced by post-translational modifications in $\alpha$-defensins. International Journal of Peptides, 2011, Article ID: 594723.

[45] Biswas, A., Liu, Y.J., Hao, L., et al. (2010) Induction and rescue of Nod2-dependent Th1-driven granulomatous inflammation of the ileum. Proceeding of the National Academy of Sciences of the USA, 107, 14739-14744. doi:10.1073/pnas. 1003363107
[46] Wehkamp, J. and Stange, E.F. (2010) Paneth's disease. Journal of Crohn's and Colitis, 4, 523-531. doi:10.1016/j.crohns.2010.05.010

[47] Zilbauer, M., Jenke, A., Wenzel, G., et al. (2011) Intestinal alpha-defensin expression in pediatric inflammatory bowel disease. Inflammatory Bowel Diseases, 17, 2076-2086. doi:10.1002/ibd.21577

[48] You, X.J., Bryant, P.J. and Jurnak, F. (2007) Expression of Wnt pathway components frizzled and disheveled in colon cancer arising in patients with inflammatory bowel disease. Oncology Reports, 18, 691-694.

[49] Sato, T., van, Es, J.H. and Snippert, H.J. (2011) Paneth cells constitute the niche for Lgr5 stem cells in intestinal crypts. Nature, 469, 415-418.

[50] Beisner, J., Stange, E.F. and Wehkamp, J. (2010) Paneth cell function-Implications in pediatric Crohn disease. $A n$ International Journal of Gastroenterology and Hepatology on Microbes, 2, 47-51. doi:10.4161/gmic.2.1.14649

[51] Wehkamp, J., Wang, G., Kübler, I., et al. (2007) The Paneth cell alpha-defensin deficiency of ileal Crohn's disease is linked to Wnt/Tcf-4. Journal of Immunology, 179, 3109-3118.

[52] Kanmura, S., Uto, H., Numata, M., et al. (2009) Human neutrophil peptides 1-3 are useful biomarkers in patients with active ulcerative colitis. Inflammatory Bowel Diseases, 15, 909-917. doi:10.1002/ibd.20854

[53] Inaba, Y., Ashida, T., Ito, T., et al. (2010) Expression of the antimicrobial peptide alpha-defensin/cryptdins in intestinal crypts decreases at the initial phase of intestinal inflammation in a model of inflammatory bowel disease, IL-10-deficient mice. Inflammatory Bowel Diseases, 16, 1488-1495. doi:10.1002/ibd.21253

[54] Yamaguchi, N., Isomoto, H., Mukae, H., et al. (2009) Concentrations of alpha- and beta-defensins in plasma of patients with inflammatory bowel disease. Inflammation Research, 58, 192-197. doi:10.1007/s00011-008-8120-8

[55] Ou, G., Baranov, V., Lundmark, E., et al. (2009) Contribution of intestinal epithelial cells to innate immunity of the human gut - Studies on polarized monolayers of colon carcinoma cells. Scandinavian Journal of Immunology, 69, 150-161. doi:10.1111/j.1365-3083.2008.02208.x

[56] Zhang, H.H., Yang, X.M., Xie, Q.M., et al. (2010) The potent adjuvant effects of chicken beta-defensin-1 when genetically fused with infectious bursal disease virus VP2 gene. Veterinary Immunology and Immunopathology, 136, 92-97. doi:10.1016/j.vetimm.2010.02.018

[57] Kocsis, A.K., Lakatos, P.L., Somogyvári, F., et al. (2008) Association of beta-defensin 1 single nucleotide polymerphisms with Crohn's disease. Scandinavian Journal of Gastroenterology, 43, 299-307.

[58] Rahman, A., Fahlgren, A., Sitohy, B., et al. (2007) Betadefensin production by human colonic plasma cells: A new look at plasma cells in ulcerative colitis. Inflammatory Bowel Diseases, 13, 847-855. doi:10.1002/ibd.20141

[59] Gutiérrez, A., Holler, E., Zapater, P., et al. (2011) Antimicrobial peptide response to blood translocation of bacterial DNA in Crohn's disease is affected by NOD2/ CARD15 genotype. Inflammatory Bowel Diseases, 17, 
1641-1650.

[60] Chamaillard, M. and Dessein, R. (2011) Defensins couple dysbiosis to primary immunodeficiency in Crohn's disease. World Journal of Gastroenterology, 17, 567-571. doi:10.3748/wig.v17.i5.567

[61] Semple, F., Webb, S., Li, H.N., et al. (2010) Human betadefensin 3 has immunosuppressive activity in vitro and in vivo. European Journal of Immunology, 40, 1073-1078. doi:10.1002/eji.200940041

[62] Chang, Y.Y. and Ouyang, Q. (2008) Expression and significance of mucosal beta-defensin-2, TNFalpha and IL1beta in ulcerative colitis. The Chinese Journal of Internal Medicine, 47, 11-14.

[63] Salzman, N.H., Underwood, M.A. and Bevins, C.L. (2007) Paneth cells, defensins, and the commensal microbiota: A hypothesis on intimate interplay at the intestinal mucosa. Seminars in Immunology, 19, 70-83. doi:10.1016/j.smim.2007.04.002

[64] Aldhous, M.C., Noble, C.L. and Satsangi, J. (2009) Dysregulation of human $\beta$-defensin-2 protein in inflammatory bowel disease. Public Library of Science Pathogens One, 4, e6285. doi:10.1371/journal.pone.0006285

[65] Gersemann, M., Wehkamp, J., Fellermann, K., et al. (2008) Crohn's disease-defect in innate defence. World Journal of Gastroenterology, 14, 5499-5503. doi:10.3748/wjg. 14.5499

[66] Schneider, J.J., Unholzer, A., Schaller, M., et al. (2005) Human defensins. The Journal of Molecular Medicine, 83, 587-595. 